\title{
Factors associated with duration of breastfeeding
}

\author{
Roberto G. Chaves, ${ }^{1}$ Joel A. Lamounier, ${ }^{2}$ Cibele C. César ${ }^{3}$
}

\begin{abstract}
Objectives: To determine rates of exclusive breastfeeding and of complementary feeding and to identify variables that interfere with breastfeeding in the municipality of Itaúna, MG, Brazil.

Methods: A longitudinal study was undertaken enrolling 246 women who gave birth at the maternity unit of the Manoel Gonçalves Hospital, in Itaúna, MG. The mothers and their infants were seen monthly for the first 12 months after birth or until they stopped breastfeeding. Survival analysis procedures were used to study the duration of exclusive breastfeeding and of complementary feeding. The impact on breastfeeding duration of a series of co-variables was assessed by means of Cox regression modeling.
\end{abstract}

Results: The prevalence of exclusive breastfeeding at 6 months was $5.3 \%$, and for breastfeeding at 12 months it was $33.7 \%$. The median duration of exclusive breastfeeding was 40 days, and median breastfeeding duration was 237 days. Multivariate analysis demonstrated a negative association $(p<0.05)$ between duration of exclusive breastfeeding and the following variables: intended breastfeeding duration ( $<12$ months), birth weight of child $(<2,500 \mathrm{~g})$ and use of a pacifier. Shorter breastfeeding duration was associated $(p<0.05)$ with maternal age ( $<20$ years), number of prenatal consultations ( $<5$ and $>9$ consultations), use of alcohol or tobacco, delay before first feed ( $>6$ hours) and use of a pacifier.

Conclusions: Breastfeeding rates in Itaúna (MG) are well below those recommended by the World Health Organization. The principal variables with a negative relationship with duration of exclusive breastfeeding and of complementary feeding are related to mother and baby health care and, therefore, interventions are possible.

J Pediatr (Rio J). 2007;83(3):241-246: Breastfeeding, lactation, weaning.

\section{Introduction}

Breastfeeding is a practice that has been around for thousands of years and which offers well-known nutritional, immunological, cognitive, economic and social benefits. These benefits are only taken advantage of to the full when breastfeeding continues for at least 2 years, being the sole means of feeding infants for their first six months of life. ${ }^{1}$ Studies conducted nationally have shown that, despite a tendency towards improvement, breastfeeding rates in Brazil are well below the levels considered ideal by the World Health Organization (WHO). ${ }^{2,3}$
Research into demographic and socioeconomic variables and factors related to healthcare and to the habits of mothers and babies on a populational level can be of great utility to identifying factors related to duration of exclusive breastfeeding or complementary feeding. They can, therefore, be useful tools in the quest to increase breastfeeding rates in our country. Nevertheless, regional differences in breastfeeding practices underscore the need for focused diagnoses that can guide the taking of intervention measures aimed at promoting, supporting and protecting breastfeeding.

1. Mestre, Universidade Federal de Minas Gerais (UFMG), Belo Horizonte, MG, Brasil. Professor auxiliar, Universidade de Itaúna, Itaúna, MG, Brasil.

2. PhD, University of California (UCLA), Los Angeles, CA, USA. Professor titular, Faculdade de Medicina, UFMG, Belo Horizonte, MG, Brasil.

3. PhD, UFMG, Belo Horizonte, MG, Brasil. Professora adjunta, Instituto de Ciências Exatas, UFMG, Belo Horizonte, MG, Brasil.

Manuscript received Jul.05.2006, accepted for publication Dec.13.2006.

Suggested citation: Chaves RG, Lamounier JA, César CC. Factors associated with duration of breastfeeding. J Pediatr (Rio J). $2007 ; 83(3): 241-246$.

doi 10.2223/JPED. 1610 
The objective of this study was to determine rates of exclusive breastfeeding and of complementary feeding and to identify variables that possibly interfere with breastfeeding practices in Itaúna, MG, Brazil.

\section{Methods}

This was a longitudinal study of women who gave birth at the maternity unit of the Manoel Gonçalves de Souza Moreira Hospital, which is the only hospital in the municipality of Itaúna. Itaúna is located $72 \mathrm{~km}$ from Belo Horizonte, in the metalworking zone of midwestern Minas Gerais state and has approximately 80,000 inhabitants. The hospital's clientele come from a variety of social strata, but classes with lower purchasing power predominate. Mothers and their babies were followed for the first 12 months after delivery or until breastfeeding ceased if this took place first.

This article was extracted from a more extensive research project that aimed to assess the influence of medication on breastfeeding duration. In response to the non-existence of parameters from which to calculate sample size, the following values were adopted: $5 \%$ level of significance $(\alpha)$; power (1- $\beta$ ) of $90 \%$; subjects enrolled for 3 months; subjects followed up for 12 months after enrollment, losses of $20 \%$; a $30 \%$ probability of that mothers on medication would be breastfeeding at the end of the study and a probability of $70 \%$ for those not medicated; and a probability of being on medication of $25 \%$. Based on these parameters, the sample size was calculated at 252 mothers.

The sample was selected between 1 June 2003 and 4 September 2003 and included mothers resident in Itaúna who gave birth at the hospital's maternity unit. From the total number of subjects the following were lost: five mothers could not be located for the first interview after hospital discharge and one whose child died 40 hours after birth. A further eight of the 246 women initially enrolled were lost to follow-up; five because they moved away from the town; three because they could not be found; and 83 were censored due to the ending of the study. Therefore, accurate information about duration of overall breastfeeding was obtained from 155 women.

Data collection was carried out at the maternity unit by the researcher in conjunction with members of the Universidade de Itaúna Physiotherapy Department. These academics were trained to apply the questionnaires during interviews with 20 mothers as part of a pilot study. Quality control was carried out at weekly meetings for the first 8 weeks of data collection and fortnightly thereafter.

Data of interest were obtained from medical records and interviews conducted during the immediate postnatal period. These data will provide information on demographic and socioeconomic characteristics and factors related to healthcare services and mothers' and babies' habits. After discharge from the maternity unit, mothers were followed up by means of contact by telephone or by home visits.

The variables studied were as follows: origin; health insurance; maternal age; skin color; marital status; breast surgery; number of pregnancies and births; gestational age; prenatal care; family income and electricity consumption; basic sanitation; maternal and paternal education; maternal employment; maternity leave; family support; knowledge of breastfeeding techniques; intention of breastfeeding; time passed between birth and first breastfeed; use of medication, alcohol and tobacco by mother; use of a pacifier; intercurrent conditions; sex and birth weight of child.

The following WHO definitions of breastfeeding categories were adopted for this study: ${ }^{1}$

- exclusive breastfeeding: the child is fed exclusively on human milk from its mother or wet-nurse, or on expressed milk, with no other liquids or solids, with the exception of drops, syrups, mineral supplements and medications;

- predominant breastfeeding : the child is fed on human milk and other liquids, such as water, teas, fruit juices and medications, but receives no other type of milk;

- full breastfeeding: exclusive breastfeeding plus predominant breastfeeding;

- complementary feeding: the child is fed on human milk and other solid or semi-solid foods;

- breastfeeding: the child is fed human milk (from the breast or expressed) irrespective of whether or not other foods are also given.

The term full weaning was adopted to describe complete cessation of breastfeeding. ${ }^{4}$

The project was approved by the Ethics Committee at the Manoel Gonçalves de Souza Moreira Hospital, the UFMG Pediatrics Department and the UFMG Research Ethics Committee.

Statistical analysis of the data was carried out using SPSS, ${ }^{5}$ version 9.0. Survival analysis procedures were applied to duration of exclusive breastfeeding and breastfeeding. Breastfeeding curves were plotted using the Kaplan-Mayer method, which provides medians for duration of exclusive breastfeeding and of breastfeeding. Curves were compared using log rank testing. The effect of co-variables on breastfeeding duration was assessed using Cox regression modeling. Variables were included in the multivariate regression model if they exhibited a correlation with an outcome with $p<0.25$ in the bivariate analysis. The cutoff for significance was set at $5 \%$. 


\section{Results}

\section{Duration of exclusive breastfeeding and of breastfeeding}

All of the women were breastfeeding at the time of hospital discharge, although only 241 (98\%) were doing so exclusively. Prevalence rates of exclusive breastfeeding at the first, fourth and sixth months of life were 62.6, 19.5 and $5.3 \%$ respectively. Full breastfeeding rates for the same periods were $77.2,42.3$ and $15 \%$. Prevalence rates of overall breastfeeding for the first, fourth, sixth and twelfth months were 93.5, 75.2 58.9 and 33.7\%, respectively (Figure 1).

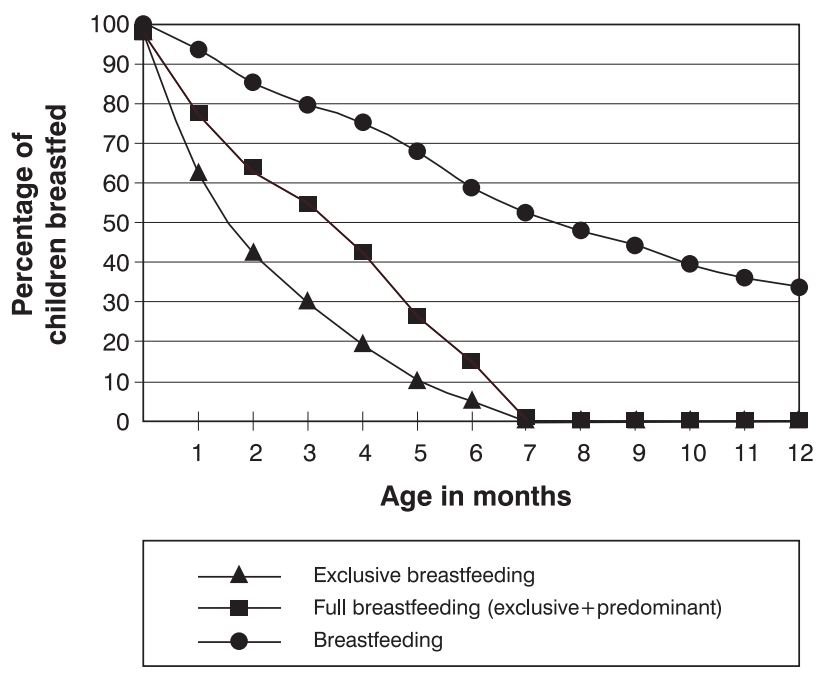

Figure 1 - Prevalence rates for exclusive breastfeeding, full breastfeeding and breastfeeding in Itaúna, MG, Brazil, 2003

Median duration of exclusive breastfeeding was 40 days, and for full breastfeeding it was 95 days. Median duration of breastfeeding was 237 days.

\section{Factors related to exclusive breastfeeding}

According to the bivariate analysis, variables that exhibited positive, statistically significant associations with shorter duration of exclusive breastfeeding were: birth weight of child $<2,500 \mathrm{~g}(\mathrm{p}=0.03)$, incorrect answer to question on breastfeeding technique $(p=0.012)$, intention to breastfeed for less than 2 years $(p=0.009)$, use of alcohol or tobacco $(p=0.036)$ and use of a pacifier $(p=0.002)$.

As can be observed in Table 1, after the multivariate analysis, variables with statistically significant $(p<0.05)$ negative associations with duration of exclusive breastfeeding were: intention to breastfeed for less than 2 years $(p=0.002)$, birth weight of child $<2,500 \mathrm{~g}(\mathrm{p}=0.019)$ and use of a pacifier $(p=0.007)$.
Table 1 - Variables related with duration of exclusive breastfeeding $(\mathrm{p}<0.05)$ according to multivariate analysis, Itaúna, MG, 2003

\begin{tabular}{lll}
\hline Variables & RR (95\%CI) & p* \\
\hline & & \\
$\begin{array}{l}\text { Intention to breastfeed } \\
(\geq 24 \text { months })\end{array}$ & & \\
$\quad<12$ months & $1.67(1.20-2.33)$ & 0.002 \\
$\quad 12-23$ months & $1.74(1.23-2.47)$ & 0.002 \\
$\begin{array}{l}\text { Birth weight of child } \\
\text { (<2,500 g) }\end{array}$ & $1.92(1.11-3.33)$ & 0.019 \\
Use of a pacifier & $1.49(1.11-2.00)$ & 0.007 \\
& &
\end{tabular}

$95 \% \mathrm{CI}=$ confidence interval de $95 \% ; \mathrm{RR}=$ relative risk.

* Calculated using the log rank test.

\section{Factors related to breastfeeding}

According to the bivariate analysis, variables that exhibited negative statistically significant associations with duration of breastfeeding were: maternal age less than 20 years $(p=0.001)$, gestational age $<37$ weeks $(p=0.039)$, less than five or more than nine prenatal consultations $(p=0.002)$, first suckled more than 6 hours after birth $(p=0.032)$, newborn with intercurrent condition $(p=0.001)$, use of alcohol or tobacco $(p=0.001)$ and use of a pacifier $(p=0.000)$.

The multivariate analysis demonstrated positive, statistically significant associations between shorter breastfeeding duration and the following variables: maternal age less than 20 years $(p=0.009)$, less than five or more than nine prenatal consultations ( $p=0.001$ ), use of alcohol or tobacco ( $p=0.001)$, first suckled more than 6 hours after birth $(p=0.038)$ and use of a pacifier $(p=0.000)$. These results are listed in Table 2.

\section{Discussion}

The findings of this study were compared with published data, in particular with the results of population studies undertaken in towns geographically and demographically similar to Itaúna, although there are methodological and temporal differences between studies. Since the town has only one hospital, where almost all births take place, the sample can be considered representative of this population.

In Itaúna, the prevalence of exclusive breastfeeding at the end of the sixth month of life $(5.3 \%)$ was similar to prevalence rates observed in Ouro Preto ${ }^{6}(1.8 \%)$, Alto Jequitinhonha ${ }^{7}(0.8 \%)$ and $\mathrm{Embu}^{8}(1.6 \%)$, although lower than the $17.7 \%$ found in Feira de Santana. ${ }^{9}$ The prevalence of breastfeeding at 12 months, however, was lower than that 
observed in Ouro Preto ${ }^{6}$ (34.9\%), Montes Claros $^{7}$ (41\%) and Feira de Santana ${ }^{9}(69.2 \%)$, but higher than the prevalence of $30 \%$ found in Embu. ${ }^{8}$

Table 2 - Variables related to breastfeeding duration ( $p<0.05$ ) according to multivariate analysis, Itaúna, MG, 2003

\begin{tabular}{llc}
\hline Variables & RR (95\%CI) & p* \\
\hline $\begin{array}{l}\text { Maternal age (<20 years) } \\
\text { Number of prenatal }\end{array}$ & $1.89(1.17-3.06)$ & 0.009 \\
$\begin{array}{l}\text { consultations }(\mathrm{n}) \\
<5\end{array}$ & $0.71(0.34-1.51)$ & 0.379 \\
$\quad 5-9$ & $0.33(0.19-0.58)$ & 0.000 \\
$\begin{array}{l}\text { Delay before first } \\
\text { breastfeed (> 6 hours) } \\
\text { Use of alcohol or tobacco } \\
\text { Use of a pacifier }\end{array}$ & $1.95(1.03-3.67)$ & 0.038 \\
& $1.92(1.29-2.85)$ & 0.001 \\
\hline
\end{tabular}

$95 \% \mathrm{CI}=95 \%$ confidence interval; $\mathrm{RR}=$ relative risk

* Calculated using the log rank test.

Median duration of exclusive breastfeeding was 40 days, an intermediate position in relation to other Brazilian locations. This figure is worrying, because it demonstrates that foods such as water, teas and juices are being introduced prematurely. It is known that such supplements are unnecessary for babies' hydration needs, ${ }^{10}$ increase the risk of morbidity and mortality by infections, ${ }^{11}$ do not improve weight gain ${ }^{12}$ and reduce uptake of iron and zinc. ${ }^{13}$ Premature introduction of these and other supplementary foods, as well as complementary ones such as non-human milk, fruit and savory mashes, can reduce the contraceptive efficacy of lactational amenorrhea and also reduce breastfeeding duration. ${ }^{14}$ Furthermore, premature use of cow's milk is linked with increased risk of atopic diseases and diabetes mellitus type I. ${ }^{15}$ The great frequency with which supplementary and complementary foods are being used may be the result of cultural factors and of ignorance on the part of some health professionals of the benefits of exclusive breastfeeding until the sixth month of infants' lives.

The median duration of breastfeeding observed in Itaúna was 237 days, which is longer than the medians of 159 days in Alfenas, ${ }^{16} 180$ days in Embu, ${ }^{8} 198$ days in Ouro Preto ${ }^{6}$ and 205.9 days in São José do Rio Preto. ${ }^{17}$ It is still, nevertheless, shorter than the median durations of 261 days in Montes Claros $^{18}$ and 325.5 days in towns in Alto Jequitinhonha. ${ }^{7}$ The medians for exclusive breastfeeding and for breastfeeding in Itaúna confirm the tendency to increase these rates in our country. Nevertheless, they are well below what is recommended by the WHO. ${ }^{1}$
A negative relationship between birth weight $<2,500 \mathrm{~g}$ and duration of exclusive breastfeeding has also been described in other studies. ${ }^{7,16,18}$ The fact that low birth weight infants are exclusively breastfed for shorter periods than other infants may be the result of the increased difficulty that such babies have in suckling and also because of the belief on the part of some health professionals that the most important factor with such babies is weight gain and so infant formulae, powdered milk, cow's milk and sugar are given. This being so, in order to increase exclusive breastfeeding rates it is necessary to give greater attention to preventing conditions that make it more likely babies will be born at low weights, such as intrauterine growth restriction and premature delivery, in addition to taking measures to improve prenatal care and to reduce smoking during pregnancy. The Kangaroo Mother Care system results in greater physical and emotional contact between low weight newborn infants and their mothers and has been described as an action with a positive impact on breastfeeding. ${ }^{19}$ Another indispensable intervention is to improve the care provided by health professionals responsible for infant health to this group of mothers and babies, in the form of encouraging and supporting exclusive breastfeeding.

The fact that mothers who expressed the intention in the maternity unit of breastfeeding their children for less than 2 years exhibited shorter exclusive breastfeeding duration may by because these women were less well informed on the importance of breastfeeding and more exposed to external pressures. Furthermore, it can be postulated that mothers whose intention is to breastfeed for shorter periods are less committed to following medical guidance on duration of exclusive breastfeeding. No reports were found in the literature relating this variable with duration of exclusive breastfeeding.

The fact that adolescent women ( $<20$ years) breastfed their children for shorter periods coincides with data published by Gigante et al. ${ }^{20}$ That adult women breastfeed for longer may be due to greater experience and knowledge of breastfeeding. This should alert us to the need for greater care and attention to adolescent mothers, aiming to provide guidance, encouragement and support for breastfeeding. Wider dissemination of sexual education information could contribute to a reduction in the frequency of adolescent pregnancies.

Women who attended less than five and more than nine prenatal consultations breastfed their children for a shorter period than mothers who attended between five and nine consultations. Caldeira \& Goulart, ${ }^{18}$ in Montes Claros, observed that women who attended less than five consultations breastfed for a shorter duration than those who attended more than five $(p=0.0496)$, although only in a bivariate analysis. The fact that women who attended less 
than five prenatal consultations breastfed their children for a shorter period may be related to reduced access to the information provided during the prenatal period. Nevertheless, the association between a greater number of prenatal consultations and shorter duration of breastfeeding cannot be satisfactorily explained. However, one could speculate that these women suffer from a greater degree of anxiety and insecurity. In order to better explain this finding, it would be necessary to engage in a deeper study of this subset of patients, including the use of qualitative assessment methods.

The shorter duration of breastfeeding when newborn infants were suckled for the first time more than 6 hours after being born has also been reported by Caldeira \& Goulart ${ }^{18}$ in Montes Claros. Bautista ${ }^{21}$ also described a positive relationship between shorter delay before first feed and longer duration of breastfeeding. Figueiredo \& Goulart ${ }^{22}$ noted a positive association between lower rates of full weaning and increased number of women who were not separated from their children during the first 6 hours after birth. This fact can be explained by the beneficial effect of this first contact for the mother, leading to increased liberation of oxytocin, favorable to milk ejection, in addition to the lactogenic effect of the baby's suction. Furthermore, the importance of early contact has also been linked to strengthening the emotional bond between mother and child, which may also be responsible for increased breastfeeding duration. ${ }^{23}$ The fact that babies who start feeding early are breastfed for longer demonstrates the important role that hospital practices can play in the success of breastfeeding, reinforcing the importance an integrated rooming-in policy, allowing mother and child to remain together throughout their hospital stay. ${ }^{24}$

Women who reported in the maternity unit that they used alcohol and tobacco breastfed had shorter breastfeeding duration than those who said they did not use these drugs. Despite evidence that smoking while breastfeeding is less prejudicial than feeding with industrialized milk, ${ }^{25}$ the majority of published data links maternal smoking with shorter duration of breastfeeding. ${ }^{26}$ Furthermore, both smoking and alcohol use have been reported to be linked with reduced volume of breastmilk. ${ }^{27,28}$ Although the American Academy of Pediatrics (AAP) ${ }^{29}$ considers alcohol to be compatible with breastfeeding and permits the use of tobacco, the results of our study reinforce the importance of reducing the use of these substances by women, particularly nursing mothers. Physical and psychological factors linked to pregnancy and breastfeeding make these ideal moments for health professionals to indicate cessation of alcohol and tobacco use.

Use of pacifiers by infants was negatively associated with duration of both exclusive breastfeeding and overall breastfeeding. The analysis took account solely of whether or not the child was given a pacifier, not identifying frequency or time of usage. The fact that babies who did not use a pacifier had longer duration of exclusive breastfeeding is in agreement with published data. ${ }^{26,30}$ This fact may be related to greater confidence on the part of mothers whose babies were not given pacifiers, being less sensitive to social pressures and less anxious about their children's growth rate. Furthermore, pacifiers may be related to reduction in milk production, as a result of reduced frequency of feeds. ${ }^{30}$ Silveira \& Lamounier ${ }^{26}$ performed a review of the literature on studies that associate pacifiers with shorter breastfeeding duration. All eight studies found reported a statistically significant association. Soares et al. ${ }^{30}$ found a 2.8 times greater risk of full weaning before the sixth month by children who were still being breastfed at 1 month, but who were using a pacifier. Therefore, the pacifier use may be camouflaging breastfeeding difficulties or maternal anxiety and insecurity about the feeding process, facts which should alert us to the need to solve such problems. It is to be desired that studies be carried out to evaluate this theme in greater depth, including the use of qualitative assessment methods. Therefore, mothers should be better informed of the serious consequences for successful breastfeeding of giving pacifiers to infants - a habit that is apparently innocuous and which is very much culturally acceptable.

\section{Final comments}

The determination of indicators and variables related to exclusive or overall breastfeeding duration can be a valuable instrument when planning local actions and policies aimed at improving breastfeeding rates. This study, in common with other Brazilian studies, demonstrates that breastfeeding rates are well below those recommended by the WHO. It also reveals that the principal variables negatively related with duration of exclusive breastfeeding and complementary feeding are susceptible to intervention. Therefore, improving the quality of the healthcare provided to mothers and their babies can be considered an extremely important measure for increasing breastfeeding rates.

\section{References}

1. World Health Organization. Report of the expert consultation on the optimal duration of exclusive breastfeeding: conclusions and recommendations. Geneva: WHO; 2001.

2. Brasil, Ministério da Saúde. Prevalência de aleitamento materno nas capitais brasileiras e no Distrito Federal. Brasília: Ministério da Saúde; 2001.

3. Lamounier JA. Tendências do aleitamento materno no Brasil. Rev Med Minas Gerais. 1999;9:59-66.

4. World Health Organization, United Children's Fund. Complementary feeding of young children in developing countries: a review of current scientific knowledge. Geneva: WHO/NUT/98.1; 1998. 
5. SPSS for Windows. Release 9.0. Chicago: SPSS; 1998.

6. Passos MC, Lamounier JA, Silva CAM, Freitas SN, Baudson MFR. Práticas de amamentação no município de Ouro Preto, Minas Gerais, Brasil. Rev Saude Publica. 2000;34:617-22.

7. Silveira FJF, Lamounier JA. Prevalência do aleitamento materno e prática de alimentação complementar em crianças com até 24 meses de idade na região do Alto Jequitinhonha, Minas Gerais. Rev Nutr. 2004;17:437-47.

8. Pedroso GC, Puccini RF, Silva EMK, Silva NN, Alves MCGP. Prevalência de aleitamento materno e introdução precoce de suplementos alimentares em área urbana do Sudeste do Brasil, Embu, São Paulo. Rev Bras Saude Matern Infant. 2004;4:45-58.

9. Vieira GO, Almeida JAG, Silva LR, Cabral VA, Netto PVS. Fatores associados ao aleitamento materno e desmame em Feira de Santana, Bahia. Rev Bras Saude Matern Infant. 2004;4:143-50.

10. Brown KH, Creed de Kanashiro H, del Aguila R, Lopez de Romana G, Black RE. Milk consumption and hydration status of exclusively breast-fed infants in a warm climate. J Pediatr. 1986;108:677-80.

11. Arifeen S, Black RE, Antelman G, Baqui A, Caulfield L, Becker S. Exclusive breastfeeding reduces acute respiratory infection and diarrhea deaths among infants in Dhaka slums. Pediatrics. 2001;108:E67.

12. Cohen RJ, Brown KH, Canahuati J, Rivera LL, Dewey KG. Effects of age of introduction of complementary foods on infant breast milk intake, total energy intake, and growth: a randomised intervention study in Honduras. Lancet. 1994;344:288-93.

13. Black RE, Victora CG. Optimal duration of exclusive breast feeding in low income countries. BMJ. 2002;325:1252-3.

14. Rea MF. Os benefícios da amamentação para a saúde da mulher. J Pediatr (Rio J). 2004;80:S142-6.

15. Monte CMG, Giugliani ERJ. Recomendações para a alimentação da criança amamentada. J Pediatr (Rio J). 2004;80(5 Supl):S131-41.

16. Pereira FA. Aspectos sociodemográficos e médico-hospitalares do aleitamento materno em Alfenas, Minas Gerais [dissertação]. Alfenas: Faculdade de Medicina da UNIFENAS; 2000.

17. Figueiredo MG, Sartorelli DS, Zan TAB, Garcia E, Silva LC, Carvalho FLP, et al. Inquérito de avaliação rápida das práticas de alimentação infantil em São José do Rio Preto/SP, Brasil. Cad Saude Publica. 2004;20:172-9.

18. Caldeira AP, Goulart EM. A situação do aleitamento materno em Montes Claros, Minas Gerais: estudo de uma amostra representativa. J Pediatr (Rio J). 2000;76:65-72.
19. Venâncio SI, de Almeida H. Método mãe canguru: aplicação no Brasil, evidências científicas e impacto sobre o aleitamento materno. J Pediatr (Rio J). 2004;80:S173-80.

20. Gigante DP, Victora CG, Barros FC. Nutrição materna e duração da amamentação em uma coorte de nascimento de Pelotas/RS. Rev Saude Publica. 2000; 34:259-65.

21. Bautista LE. Duration of maternal breast-feeding in the Dominican Republic. Rev Panam Salud Publica. 1997;1:104-11.

22. Figueiredo LM, Goulart EM. Análise da eficácia do Programa de Incentivo ao Aleitamento Materno em um bairro periférico de Belo Horizonte (Brasil): 1980/1986/1992. J Pediatr (Rio J). 1995;71:203-8.

23. Widstrom AM, Wahlberg V, Matthiensen AS, Eneroth $P$, UvnasMoberg K, Werner S, et al. Short-term effects of early suckling and touch of the nipple on maternal behavior. Early Hum Dev. $1990 ; 21: 153-63$.

24. Organização Mundial da Saúde. Evidências científicas dos dez passos para o sucesso no aleitamento materno. Brasília: OPAS; 2001.

25. Batstra L, Neeleman J, Hadders-Algra M. Can breast feeding modify the adverse effects of smoking during pregnancy on the child's cognitive development? J Epidemiol Community Health. 2003; 57:403-4.

26. Silveira FJF, Lamounier JA. Influência do uso da chupeta e do tabagismo materno na amamentação: revisão de literatura. Rev Med Minas Gerais. 2003;13:120-8.

27. Vio F, Salazar G, Infante C. Smoking during pregnancy and lactation and its effects on breast-milk volume. Am J Clin Nutr. 1991;54:1011-6.

28. Cobo E. Effect of different doses of ethanol on the milk-ejecting reflex in lactating women. Am J Obstet Gynenol. 1973;115:817-21.

29. American Academy of Pediatrics Committee on Drugs. Transfer of drugs and other chemicals into human milk. Pediatrics. 2001; 108:776-89.

30. Soares ME, Giugliani ER, Braun ML, Salgado AC, de Oliveira AP, de Aguiar PR. Uso de chupetas e sua relação com o desmame precoce em população de crianças nascidas Hospital Amigo da Criança. J Pediatr (Rio J). 2003;79:309-16.

Correspondence:

Roberto Gomes Chaves

Rua Mariângela Medeiros, 50, Centro

CEP 35680-457 - Itaúna, MG - Brazil

Tel.: +55 (37) 3241.5194

Fax: +55 (37) 3242.1064

E-mail: robertogchaves@uol.com.br 